\title{
Şeker Pancarında Farklı Hasat Zamanı ve Tarlada Depolama Sürelerinin Verim ve Şeker Oranı Üzerine Etkileri
}

\author{
Şerif Ferhat Koçak Engin Gökhan Kulan Mehmet Demir Kaya*
}

\author{
Eskişehir Osmangazi Üniversitesi, Ziraat Fakültesi Tarla Bitkileri Bölümü, Eskişehir \\ *Sorumlu yazar: demirkaya76@hotmail.com
}

Geliş Tarihi: 15.05.2019

Kabul Tarihi: 31.10 .2019

$\ddot{\mathbf{O z}}$

$\mathrm{Bu}$ araştırmada, farklı hasat zamanları ve tarlada bekletme sürelerinin şeker pancarının verimi ve şeker oranı üzerine etkileri ile ağırlık kaybındaki değişimler belirlenmiştir. Araştırmada materyal olarak Bernache şeker pancarı çeşidi kullanılmıştır. Hasat zamanları 15 Eylül, 29 Eylül, 13 Ekim ve 27 Ekim olarak belirlenmiş ve hasat edilen şeker pancarı kökleri 3, 7, 14, 21 ve 28 gün süreyle tarla koşullarında bekletilmiştir. Pancar verimi, şeker oranı, şeker verimi, ağırlık kaybı ve günlük ağırlık kaybı özellikleri incelenmiştir. Pancar veriminin hasat zamanlarından önemli şekilde etkilenmediği belirlenmiştir. Bununla birlikte, tarlada bekletme süresinin uzaması pancar ağırlığını azaltırken, şeker oranını artırmıştır. Depolama süresinin uzamasıyla şeker oranı \%13,71'den \%19,68'e yükselmiş, kök gövde ağırlığı ise \%22,11 oranında azalmıştır. Şeker verimi ise hasat zamanı geciktikçe ve bekletme süresi uzadıkça artış göstermiştir. En yüksek şeker verimi (1825 kg/da) 27 Ekim tarihinde hasat edilen ve tarlada 3 gün süreyle bekletilen pancarlardan elde edilmiştir. Hasat zamanındaki gecikme, pancar veriminde önemli bir artış sağlamamış ancak, şeker oranını yükseltmiştir. Sonuç olarak, Eskişehir koşullarında şeker pancarı hasadının Ekim ayının ikinci yarısında yapılması ve yedi günden fazla tarlada bekletilmemesi gerektiği söylenebilir.

Anahtar Kelimeler: Beta vulgaris, hasat zamanı, depolama, şeker verimi, verim kaybı

\section{The Effects of Harvest Date and Field Storage Duration on Yield and Sugar Rate of Sugar Beet \\ Abstract}

This study aimed to determine the effects of different harvest dates and field storage durations on root yield, sugar content of sugar beet and the changes in weight loss during field storage. Sugar beet variety Bernache was used as material in the study. The harvest dates were determined as September 15, September 29, October 13 and October 27, and the roots were stored for 3, 7, 14, 21 and 28 days after harvest under field conditions. Root yield, sugar content, sugar yield, yield loss and yield loss per day were investigated. The root yield did not significantly affected by harvest dates. However, increased storage duration resulted in an increase in sugar content while the root weight was clearly decreased. Depending on delayed storage, the sugar content improved from $13.71 \%$ to $19.68 \%$ while the root weight was reduced by $22.11 \%$. The sugar content increased as the harvest date delayed and the storage period prolonged. The highest sugar yield $(1825 \mathrm{~kg} / \mathrm{da})$ was obtained from the harvest on October 27 and stored for 3 days. The delay of harvest date was effective in increasing the sugar content rather than promoting the root yield. It was concluded that sugar beet has to be harvested in the second half of October and it should not be stored more than seven days under Eskişehir conditions.

Keywords: Beta vulgaris, harvest date, storage, sugar yield, yield loss

\section{Giriş}

Dünyada üretilen şekerin yaklaşı \% \%79'u şeker kamışından, \%21'i ise şeker pancarından elde edilmektedir. 2018/19 döneminde 178 milyon ton beyaz şeker üretilmiş olup, bunun 140 milyon ton'u şeker kamışından, 38 milyon ton'u şeker pancarından elde edilmiştir (Anonim, 2017 a; Anonim, 2019 a). Aynı yıl içerisinde ticareti yapılan şeker miktarı ise 59 milyon ton olarak gerçekleşmiştir. Dünyanın en büyük şeker üretici ülkeleri olan Brezilya ve Hindistan'da şekerin tamamı şeker kamışından üretilmekte ve bu iki ülke yaklaşık 63 milyon ton şeker ile dünya şeker üretiminin \%35'ini karşılamaktadır (Anonim 2019 a). Ülkemizde ise iklim ve toprak şartlarının uygunluğu nedeniyle üretilen şekerin tamamı, şeker pancarından elde edilmektedir (Anonim, 2018 a). 2017 y1lı verilerine göre, şeker pancarı ekim alanı 3.392.171 dekar, üretimi 20.828 .316 ton ve verimi $6147 \mathrm{~kg} / \mathrm{da}$ olarak gerçekleşmiştir (Anonim, 2018 b). 2017 yılında üretilen şeker pancarından ise 2.772.258 ton şeker 
elde edilmiştir (Anonim, 2017 b). Bu şeker miktarı ile ülkemiz, dünyada pancar şekeri üreten ülkeler arasında beşinci sırada yer almaktadır.

Şeker pancarı tarımında temel amaç öncelikle, yüksek kök-gövde verimi ve şeker oranına sahip pancar üretimi yapmaktır. Birim alandan alınacak kök-gövde verimi, üreticinin kazancını doğrudan etkilemektedir. Bunun yanında, şeker pancarında verim kadar kalite de çok önemlidir. Çünkü pancarın fiyatı, bünyesinde bulundurduğu şeker oranına göre tespit edilmektedir. Ülkemizde şeker pancarı, \%16 polar şeker oranı esas alınarak fiyatlandırılmaktadır. Bu nedenle, yüksek verim ile birlikte yüksek şeker oranı şeker pancarı tarımında dikkat edilmesi gereken en önemli konuları oluşturmaktadır.

Şeker pancarı tarımında verim ve kaliteyi belirleyen başlıca faktörler iklim, toprak, çeşit ve yetiştirime teknikleridir. İklim şartları kontrol edilemediğinden, başta çeşit seçimi olmak üzere, tarla ve tohum yatağı hazırlığı, bitki sıklığı, yabanc1 ot mücadelesi, gübreleme, sulama, hastalık ve zararlılarla mücadele gibi bakım işlemlerinin uygun şekilde ve zamanında yapılması, yüksek verim ve kaliteye sahip pancar üretiminde önemli rol oynamaktadır (Haagenson ve ark., 2006; Tok ve Erkan, 2006; Anonim, 2018 c). Ayrıca, hasattan sonra şeker pancarının işlenip şeker elde edilinceye kadar geçen süredeki depolama koşulları ve süreleri de gerek verimi gerekse kaliteyi etkileyen hasat sonrası faktörlerdir (Abdollahian-Noghabi ve Zadeh, 2005; Huijbregts ve ark., 2013). Çünkü şeker pancarı kökleri, ortalama \%75 oranında su bulunması nedeniyle depolanması zor bir üründür. Uygun depolama koşullarında bile verim ve kalite olumsuz yönde etkilenebilmektedir (Kenter ve Hoffmann 2009; Barna ve ark., 2011).

Şeker pancarı birim alandan yüksek verim sağlayan bir bitkidir. Dolayısıyla hasat edilen pancarların tamamı fabrikaya veya kantara taşınması kısa sürede gerçekleştirilemez. Ayrıca, fabrikalara gelen pancarların da tamamı, fabrikanın işleme kapasitesine göre değişmekle birlikte, çoğunlukla hemen işlenememektedir (Er ve Uranbey, 1998). Bu nedenle pancarların belirli bir süre tarlada depolanması veya fabrikada silolanması gerekmektedir. Bu depolama süresi boyunca hava sıcaklığına bağlı olarak pancarlar solunum yapmaktadır. Solunum sırasında pancar bünyesindeki sakkaroz yakılarak sıcaklık ile birlikte karbondioksit ve su açığa çıkmakta ve sonuçta önemli ağırlık ve kalite kayıplarına neden olmaktadır (Arıoğlu, 2000; Huijbregts ve ark., 2013). Depolama süresinin uzunluğu, pancarın hasat zamanı ve olgunluk durumu, depolama süresince mevcut iklim faktörleri, baş kesimi iyi yapılmamış zedelenmiş ve yapraklı pancarların miktarı silo kayıplarını etkileyen başlıca faktörler arasında yer almaktadır (Huijbregts ve ark., 2013).

$\mathrm{Bu}$ çalışmanın amacı, Eskişehir koşullarında farklı zamanlarda hasat edilen pancarın tarla koşullarında depolama sürelerinin kök-gövde ağırlı̆̆ı, şeker oranı ve ağırlık kaybı üzerine etkilerini incelemektir.

\section{Materyal ve Yöntem}

Bu çalışmada materyal olarak, ülkemizde 2016 yılında tescil edilen Dirik Dış Tic. firmasının Bernache şeker pancarı çeşidi kullanılmıştır. Bernache çeşidinin, Rhizomania (Kök sakallanması) ve yaprak lekesi hastalığına (Cercospora beticola) karşı toleransl1, yüksek kök verimi ve şeker oranı sahip, makinalı hasada uygun, bitki boyu orta ve yaprakları dik gelişen özelliğe sahip olduğu bildirilmektedir (Anonim, 2019).

$\mathrm{Bu}$ araştırma, Eskişehir İlinin Odunpazarı İlçesi Kalkanlı Mahallesi’nde 2017 yılında yürütülmüştür. Deneme alanı engebesiz olup, deniz seviyesinden yüksekliği yaklaşı 900 m'dir. Deneme alanı topraklarında yapılan analiz sonuçlarına göre, deneme alanı toprăğ killi yapıya sahip olup, hafif alkali $(\mathrm{pH}=7,86)$, orta derecede kireçli, toplam tuz düzeyi zararsız, fosfor bakımından yetersiz ve potasyumca zengindir. Organik maddesi az $(\% 1,7)$ olan toprakta, drenaj problemi bulunmamaktadir.

Araştırmanın yürütüldüğü 2017 yılına ait şeker pancarı vejetasyon dönemindeki aylık ortalama sıcaklık $\left({ }^{\circ} \mathrm{C}\right)$, nispi nem $(\%)$ ve yağış $(\mathrm{mm})$ değerleri ile bunların uzun yıllar ortalaması Çizelge 1'de gösterilmiştir. 
Çizelge 1. Denemenin yürütüldüğü 2017 yılı ve uzun yıllar ortalamasına ait bazı meteorolojik değerler

\begin{tabular}{lllllll}
\hline \multirow{2}{*}{ Aylar } & \multicolumn{3}{c}{2017 Y1lı } & \multicolumn{3}{c}{ Uzun Y1llar (1970-2013) } \\
\cline { 2 - 7 } & $\begin{array}{l}\text { Sicaklık } \\
\left({ }^{\circ} \mathrm{C}\right)\end{array}$ & $\begin{array}{l}\text { Yağ1ş } \\
(\mathrm{mm})\end{array}$ & $\begin{array}{l}\text { Nispi Nem } \\
(\%)\end{array}$ & $\begin{array}{l}\text { Sicaklık } \\
\left({ }^{\circ} \mathrm{C}\right)\end{array}$ & $\begin{array}{l}\text { YağıŞ } \\
(\mathrm{mm})\end{array}$ & $\begin{array}{l}\text { Nispi Nem } \\
(\%)\end{array}$ \\
\hline Nisan & 9,7 & 58,7 & 63,4 & 9,6 & 43,1 & 62,7 \\
Mayıs & 14,3 & 55,2 & 69,5 & 14,9 & 40,0 & 59,5 \\
Haziran & 19,1 & 46,3 & 69,6 & 19,1 & 23,7 & 55,2 \\
Temmuz & 22,9 & 11,6 & 57,2 & 22,1 & 13,1 & 51,9 \\
Ağustos & 22,0 & 35,2 & 64,6 & 21,8 & 9,2 & 53,6 \\
Eylül & 19,6 & 5,1 & 55,4 & 16,7 & 18,1 & 58,4 \\
Ekim & 10,7 & 46,5 & 69,7 & 11,7 & 32,8 & 64,7 \\
Kasım & 5,4 & 26,3 & 82,3 & 5,6 & 34,0 & 70,5 \\
\hline Toplam & --- & 284,9 & --- & -- & 214,0 & -- \\
Ortalama & 15,5 & --- & 66,5 & 15,2 & --- & 60,0 \\
\hline
\end{tabular}

Nisan-Kasım döneminde toplam 284,9 mm yağış alındığı görülmektedir (Çizelge 1). Bu değer uzun yıllar ortalaması olan 214 mm'nin oldukça üzerinde gerçekleşmiştir. Nisan, Mayıs, Haziran ve Ağustos aylarında uzun yıllar ortalamasından daha yüksek yağış alınırken, Temmuz ayında daha az yağış alınmıştır. Yağışın yüksek olduğu aylarda, ortalama sıcaklık uzun yıllar ortalamasından daha düşük gerçekleşmiştir. Ancak, özellikle Nisan, Mayıs ve Haziran aylarındaki yüksek yağış ve düşük sıcaklık nedeniyle sulamalara daha geç başlanmıştır. Temmuz ayında gerçekleşen $22,9^{\circ} \mathrm{C}^{\prime}$ lik sıcaklığın, uzun yıllar ortalamasından $\left(21,7^{\circ} \mathrm{C}\right)$ daha yüksek olduğu dikkati çekmiştir. Hava nispi neminde ise artan sicaklık ve yağışla birlikte değişim gözlenmiştir.

Deneme alanı sonbaharda pullukla $20-25 \mathrm{~cm}$ derinliğinde işlenmiş ve erken ilkbaharda kazayağı ve tırmık geçirilerek ikinci toprak işleme yapılmıştır. Ekimden önce merdane çekilerek toprak ekime hazır hale getirilmiştir. Ekim, pnömatik mibzerle $45 \mathrm{~cm}$ sıra arası, $20 \mathrm{~cm}$ sıra üzeri olacak şekilde yapılmış ve çıkıştan sonra her parsel 4 m uzunluğundaki 5 sıradan oluşturulacak şekilde rotavatörle şekillendirilmiştir.

Ekim, 6 Nisan 2017 tarihinde yapılmış, yabancı otlarla mücadele etmek amacıyla ekimden önce Chloridazon $520 \mathrm{~g} / \mathrm{L}$ (Pyramin super) etken maddeli herbisit ile toprak ilaçlanmıştır. Çıkış sonras1 yabanc1 ot mücadelesi için 20 Haziran 2017 tarihinde Ethofumesate $(200 \mathrm{~g} / \mathrm{L})$ + Phenmedipham $(100 \mathrm{~g} / \mathrm{L})+$ Desmedipham $(100 \mathrm{~g} / \mathrm{L})$ etken maddelerine sahip Belvedere Forte ile ilaçlama yapılmıştır. Ekimle birlikte tüm parsellerde yaklaşı $4,5 \mathrm{~kg} / \mathrm{da} \mathrm{N}+\mathrm{P}_{2} \mathrm{O}_{5}+\mathrm{K}_{2} \mathrm{O}$ olacak şekilde 15-15-15 ile gübrelenmiştir. Üst gübre olarak \%46'llk üre gübresinden 15 Haziranda $20 \mathrm{~kg} / \mathrm{da}$ elle serpilerek ve 7 Temmuzda ilk sulamayla birlikte $7 \mathrm{~kg} / \mathrm{da}$ uygulanarak toplamda $17 \mathrm{~kg} / \mathrm{da}$ saf azot üç defada verilmiştir.

Deneme tesadüf bloklarında bölünmüş parseller deneme desenine göre 4 tekerrürlü olarak yürütülmüştür. Ana parsellere hasat zamanları (15 Eylül, 29 Eylül, 13 Ekim ve 27 Ekim), alt parsellere de tarlada bekletilerek yapılan depolama süreleri $(3,7,14,21$ ve 28 gün) yerleştirilmiştir. Kontrol olarak hasat zamanlarındaki değerler kullanılmıştır. Deneme toplam 24 konudan oluşmuş ve 4 tekerrür ile 96 parsele ayrılmıştır. Hasat zamanları belirlenirken, 2017 yılında Eskişehir Şeker Fabrikasının kampanya başlangıç tarihi olan 15 Eylül 2017 esas alınmıştır.

Tüm parsellerde çıkış tamamlandıktan sonra bitkiler 3-4 yaprak seviyesine ulaştığında el çapası ile birlikte çift çıkan bitkilere tekleme işlemi yapılmıştır. Ekimden hasada kadar geçen sürede dört defa yağmurlama sulama yapılmıştır. Şeker pancarında görülen yaprak lekesi (Cercospora beticola) hastalığına karşı 03 Ağustos 2017 tarihinde Epoxiconazole $(84 \mathrm{~g} / \mathrm{L})+$ Fenpropimorph (250 $\mathrm{g} / \mathrm{L}$ ) etken maddelerine sahip Duett Super fungusiti ile ilaçlama yapılmıştır.

Tarla koşullarında pancar köklerinin depolanması amacıyla, bütün parseller ayrı hasat edilip her parseldeki pancarların baş ve yaprak kısımları kesilerek uzaklaştırılmıştır. Pancar kök-gövdeleri file çuvalların (soğan çuvalı) içerisine yerleştirilerek her parsel için depolama öncesi ağırlıkları tartılarak kök-gövde verimi belirlenmiş ve Şekil 1'de gösterilmiştir. Kök-gövde veriminde depolamayla meydana gelen değişimleri belirlemek amacıyla başlangıç kök-gövde verimi deneme 
ortalaması olan $10.000 \mathrm{~kg} / \mathrm{da}$ 'a sabitlenmiş ve depolama süreleri sonundaki değerlerine oranlanarak kök-gövde verimleri hesaplanmıştır.

Şeker verimi, her parselin kök-gövde verimi ile şeker oranı çarpılarak söz konusu parsele ait şeker verimleri belirlenmiş ve dekara oranlanarak dekara şeker verimi hesaplanmıştır (AbdelMotagally ve Attia, 2009).

Tarlada depolama, denemenin yürütüldüğü parseller üzerinde kök-gövdelerin açıkta bekletilmesiyle gerçekleştirilmiştir. Depolama süreleri sonunda tartılarak ağırlık kayıpları belirlenmiş ve kayıp yüzdeleri hesap edilmiştir. Ayrıca, kök-gövdelerdeki günlük ağırlık kaybı aşağıdaki formül yardımıyla yüzde (\%) olarak hesaplanmıştır (Huijbregts ve ark., 2013).

Günlük Ağırlık Kaybı $=\frac{\frac{\text { Hasattaki Ağırlık Kaybı }- \text { Depolama Sonundaki Ağırlık Kaybı }}{\text { Hasattaki Ağırlık Kaybı }}}{\text { Depolama Süresi (Gün) }} \times 100$

Araştırma sonucunda, elde edilen verilerin deneme planına uygun bir şekilde Tesadüf Bloklarında Bölünmüş Parseller Deneme desenine göre varyans analizi yapılmıştır. Uygulamalar arasındaki farklılıkların önem düzeyini belirlemek amacıyla Duncan çoklu karşılaştırma testi kullanılmıştır. İstatistiksel hesaplamaların tamamı bilgisayarda MSTAT-C (Michigan State University, v. 2.10) programı kullanılarak yapılmıştır.

\section{Bulgular ve Tartışma}

Hasat zamanlarına göre şeker pancarı verim değerlerine ait varyans analiz sonuçları Çizelge 1'de, ortalama değerleri Şekil 1'de gösterilmiştir.

Çizelge 1. Farklı zamanlarda hasat edilen şekerpancarında dekar kök-gövde verimine ait varyans analiz sonuçları

\begin{tabular}{lcccc}
\hline V.K. & S.D. & K.T. & K.O. & F de ğeri \\
\hline Genel & 15 & 16.279 .282 & - & - \\
Blok & 3 & 5.125 .280 & 1.708 .427 & 1,96 \\
Hasat zamanı & 3 & 3.298 .335 & 1.099 .445 & $1,26^{\text {öd }}$ \\
Hata & 9 & 7.855 .667 & 872.852 & - \\
\hline
\end{tabular}

Öd: önemli değil

Dekara kök-gövde verimi hasat zamanlarından etkilenmemiştir. 15 Eylül'deki hasatta kökgövde verimi 9538 kg/da iken, sırasıyla 29 Eylül'de 9376 kg/da, 13 Ekim'de 10401 kg/da ve 27 Ekim tarihindeki hasatta ise $10301 \mathrm{~kg} / \mathrm{da}$ olarak elde edilmiştir. 15 Eylül'den 27 Ekim'e kadar şeker pancarından elde edilen kök-gövde verimi istatistiksel olarak önemli bulunmasa da, verimde \%8 oranında bir artış gerçekleşmiştir.

Çizelge 2. Farklı hasat zamanları ve depolama sürelerine göre incelenen özelliklere ait varyans analiz sonuçları

\begin{tabular}{|c|c|c|c|c|c|c|}
\hline \multirow[b]{2}{*}{ V.K. } & \multirow[b]{2}{*}{ S.D. } & \multicolumn{5}{|c|}{ K.O. } \\
\hline & & $\begin{array}{c}\text { Kök-gövde } \\
\text { verimi }\end{array}$ & Şeker oranı & $\begin{array}{c}\text { Şeker } \\
\text { verimi }\end{array}$ & $\begin{array}{c}\text { Ağ1rl1k } \\
\text { kayb1 }\end{array}$ & $\begin{array}{c}\text { Günlük } \\
\text { ağırlık kayb1 }\end{array}$ \\
\hline Genel & 95 & - & - & - & - & - \\
\hline Blok & 3 & 2445 & 3,05 & 232640 & 0,3 & 0,02 \\
\hline Hasat zamanı (A) & 3 & $8951335 * *$ & $31,67 * *$ & $1502925 * *$ & $879,7 * *$ & $7,68 * *$ \\
\hline Hata $_{1}$ & 9 & 58027 & 1,70 & 66005 & 5,5 & 0,12 \\
\hline Depolama süresi (B) & 5 & $13021392 * *$ & $87,89 * *$ & $54512 *$ & $1263,7 * *$ & $5,06 * *$ \\
\hline$A \times B$ & 15 & $778002 * *$ & $11,08 * *$ & $57142 * *$ & $75,9 * *$ & $0,93 * *$ \\
\hline $\mathrm{Hata}_{2}$ & 60 & 16939 & 0,69 & 20698 & 1,7 & 0,05 \\
\hline
\end{tabular}




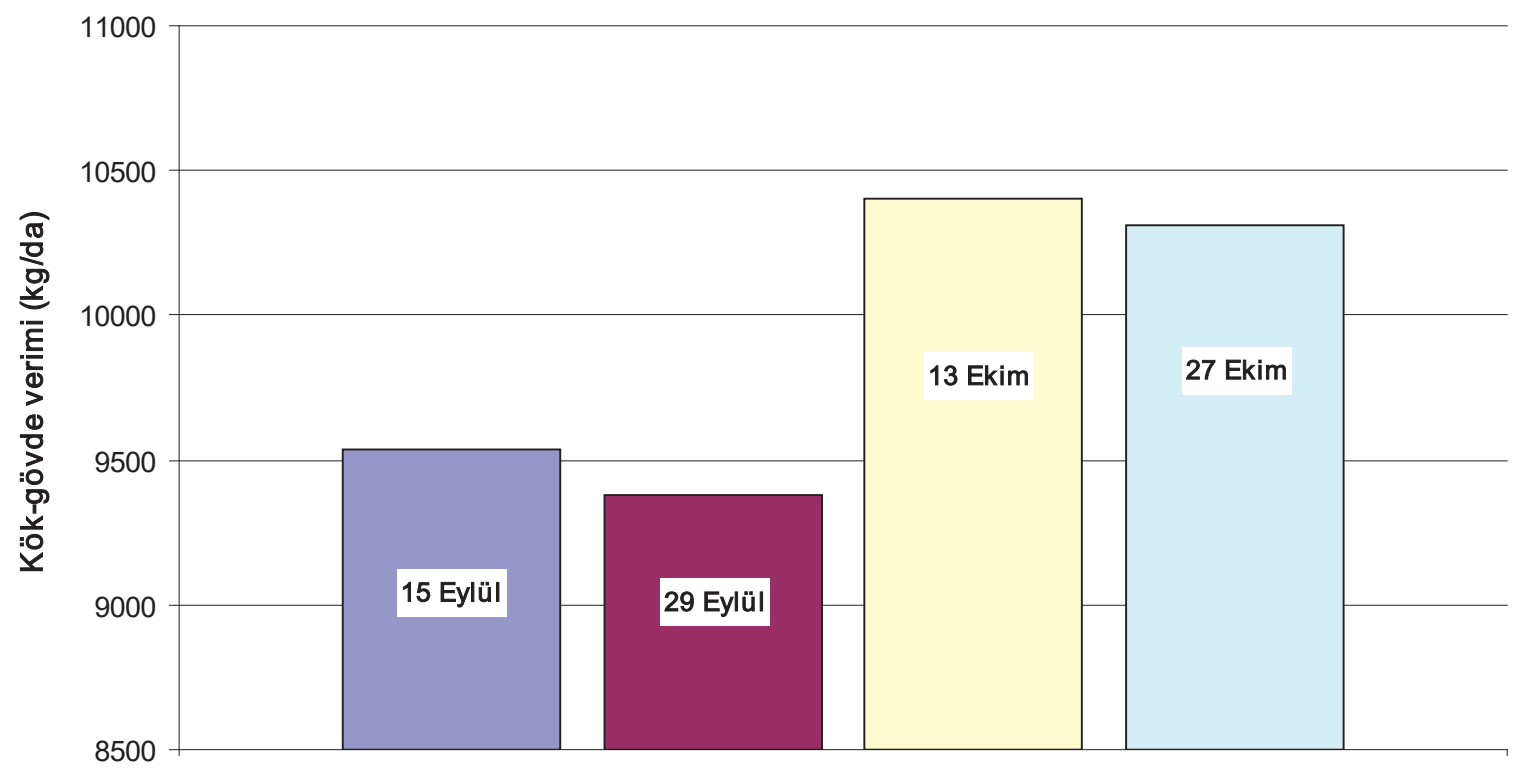

Şekil 1. Hasat zamanlarına göre şeker pancarının kök-gövde verimi

Hasat zamanları ve depolama sürelerine göre şeker pancarında incelenen özelliklere ait varyans analiz sonuçlarına göre, hasat zamanları ve hasat zamanı $\times$ depolama süresi interaksiyonu $\% 1$ düzeyinde, depolama süresi ise şeker veriminde $\% 5$ diğer özelliklerde ise $\% 1$ düzeyinde önemli bulunmuştur (Çizelge 2).

Araştırmada incelenen kök-gövde verimi, şeker oranı, şeker verimi, ağırlık kaybı ve günlük ağırlık kaybı özelliklerine ilişkin veriler ve bu verilerin değerlendirilmesi ile elde edilen sonuçlar Çizelge 2'de özetlenmiştir. Dekara pancar verimi bakımından, hasat zamanı $\times$ depolama süresi interaksiyonundan önemli şekilde etkilenmiş ve en düşük pancar verimi $6487 \mathrm{~kg} / \mathrm{da}$ ile 15 Eylül tarihinde hasat edilen ve 28 gün süreyle tarlada depolanan pancarlarda gerçekleşmiştir (Çizelge 3). 29 Eylül tarihinde hasat edilen bitkilerde en düşük dekara verim $7866 \mathrm{~kg} / \mathrm{da}$ ile 28 gün süreyle depolamadan, 13 Ekim tarihinde hasat edilen bitkilerde $7729 \mathrm{~kg} / \mathrm{da}$ ile 28 gün süreli depolamadan, 27 Ekim tarihinde hasat edilen bitkilerde ise $8990 \mathrm{~kg} / \mathrm{da}$ ile 21 gün süreli depolamadan elde edilmiştir. Erken hasat edilen bitkilerde 7 gün depolama sonunda verimde önemli kayıplar belirlenmiş, hasat zamanları ilerledikçe depolamayla verimde gerçekleşen kayıplar azalmıştır. 15 Eylül tarihinde hasat edilen pancarlarda, 28 günlük depolama sonunda $3513 \mathrm{~kg}$ 'llk, 29 Eylül tarihindeki hasatta $2134 \mathrm{~kg}$ 'l1k, 13 Ekim tarihindeki hasatta $2271 \mathrm{~kg}$ 'llk ve 27 Ekim tarihindeki hasatta ise $927 \mathrm{~kg}$ 'llk bir azalma gerçekleşmiştir. Depolamayla birlikte şeker kaybının \%19, ağırlık kaybının ise \%49'a ulaştığı Ada ve Akınerdem'in (2006) Konya koşullarında yaptığı çalışmada da belirlenmiştir. Araştırma bulgularımız bu sonuçları destekler nitelikte bulunmuştur.

Çizelge 3'de görüldüğü gibi, hasat zamanları ve depolama sürelerine göre şeker pancarı köklerindeki şeker oranı ortalamaları incelendiğinde, en düşük değerin \%12,25 ile 29 Eylülde hasat edilen ve 3 gün süreyle depolanan pancarlarda belirlenmiştir. En yüksek şeker oranı ise \%20,49 ile 15 Eylül ve 13 Ekim tarihlerinde hasat edilen ve 28 gün tarlada depolanan pancarlarda tespit edilmiştir. Hasat zamanının gecikmesi ve tarlada depolama süresinin uzaması şeker oranını arttırmıştır. Benzer bulgular Sefaoğlu ve ark. (2016) tarafından ortaya konmuş ve Kasım ayının ilk haftası yapılan hasattan en yüksek şeker oranı $(\% 18,8)$ elde edilmiştir. Kromer ve Schmitz (2004) ve Can (2016) şeker oranının hasat zamanına göre önemli oranda değiştiğini ve geç hasat edilen bitkilerde daha yüksek şeker oranı elde edildiğini saptamışlardır. Bununla birlikte, hasat zamanlarının şeker oranını etkilemediği Kıllı ve Altunbay (2012) tarafindan bildirilmiştir. Erken hasatta (15 ve 29 Eylül) 14 gün ve daha uzun sürede, 13 Ekim'deki hasatta 3 gün ve 27 Ekim'de hasat edilen bitkilerde ise hasat edildiği günde şeker oranı şeker fabrikasının alıma esas şeker oranı olan \%16'nın üzerinde saptanmıştır. Depolama bakımından elde ettiğimiz sonuçlar gölgede veya güneş altında depolanan pancarlarda şeker oranı ve şeker kazanımı artarken ağırlıklarının azaldığını belirleyen Sarwar ve ark.'nın (2008) bulgularını destekler niteliktedir. 
Çizelge 3. Farklı hasat zamanları ve depolama süreleri sonunda incelenen özelliklere ait ortalamalar

\begin{tabular}{|c|c|c|c|c|c|}
\hline \multirow{2}{*}{$\begin{array}{l}\text { Depolama } \\
\text { Süreleri }\end{array}$} & \multicolumn{4}{|c|}{ Hasat Zamanları } & \multirow{2}{*}{ Ortalama } \\
\hline & 15 Eylül & 29 Eylül & 13 Ekim & 27 Ekim & \\
\hline \multicolumn{6}{|c|}{ Kök-gövde verimi (kg/da) } \\
\hline Kontrol & $10000^{\mathrm{ab}}$ & $10000^{\mathrm{ab}}$ & $10000^{\mathrm{ab}}$ & $10000^{\mathrm{ab} *}$ & $10000^{\mathrm{A}}$ \\
\hline 3 gün & $9296^{\mathrm{cd}}$ & $10126^{\mathrm{a}}$ & $9443^{c}$ & $9852^{\mathrm{b}}$ & $9679^{\mathrm{B}}$ \\
\hline 7 gün & $7813^{\mathrm{ij}}$ & $9394^{\text {cd }}$ & $8664^{\mathrm{g}}$ & $9410^{\text {cd }}$ & $8820^{\mathrm{C}}$ \\
\hline 14 gün & $7110^{\mathrm{k}}$ & $8735^{\mathrm{g}}$ & $8203^{\mathrm{h}}$ & $9234^{\text {de }}$ & $8320^{\mathrm{D}}$ \\
\hline 21 gün & $7187^{\mathrm{k}}$ & $7932^{\mathrm{i}}$ & $7974^{\mathrm{i}}$ & $8990^{\mathrm{f}}$ & $8021^{\mathrm{E}}$ \\
\hline 28 gün & $6487^{1}$ & $7866^{\mathrm{ij}}$ & $7729^{j}$ & $9073^{\text {ef }}$ & $7789^{\mathrm{F}}$ \\
\hline Ortalama & $7982^{\mathrm{D}}$ & $9009^{\mathrm{B}}$ & $8669^{C}$ & $9427^{\mathrm{A}}$ & - \\
\hline \multicolumn{6}{|c|}{ Şeker oranı (\%) } \\
\hline Kontrol & $12,72^{\mathrm{i}}$ & $12,97^{\mathrm{i}}$ & $12,69^{i}$ & $16,45^{\mathrm{f}}$ & $13,71^{\mathrm{F}}$ \\
\hline 3 gün & $12,98^{\mathrm{i}}$ & $12,25^{\mathrm{i}}$ & $16,70^{\mathrm{f}}$ & $17,54^{\mathrm{ef}}$ & $14,86^{\mathrm{E}}$ \\
\hline 7 gün & $14,84^{\mathrm{g}}$ & $13,50^{\mathrm{hi}}$ & $18,55^{\mathrm{b}-\mathrm{e}}$ & $17,55^{\text {ef }}$ & $16,11^{\mathrm{D}}$ \\
\hline 14 gün & $17,72^{\text {ef }}$ & $14,44^{\mathrm{gh}}$ & $19,41^{\mathrm{abc}}$ & $17,52^{\text {ef }}$ & $17,27^{\mathrm{C}}$ \\
\hline 21 gün & $19,64^{\text {ab }}$ & $19,23^{\mathrm{a}-\mathrm{d}}$ & $19,22^{\mathrm{a}-\mathrm{e}}$ & $18,25^{\text {cde }}$ & $19,08^{\mathrm{B}}$ \\
\hline 28 gün & $20,49^{\mathrm{a}}$ & $19,67^{\mathrm{ab}}$ & $20,49^{\mathrm{a}}$ & $18,06^{\mathrm{de}}$ & $19,68^{\mathrm{A}}$ \\
\hline Ortalama & $16,40^{\mathrm{B}}$ & $15,34^{\mathrm{C}}$ & $17,85^{\mathrm{A}}$ & $17,56^{\mathrm{A}}$ & - \\
\hline \multicolumn{6}{|c|}{ Şeker verimi (kg/da) } \\
\hline Kontrol & $1292^{\mathrm{efg}}$ & $1219^{\mathrm{e}-\mathrm{h}}$ & $1323^{\text {efg }}$ & $1692^{\mathrm{ab}}$ & $1382^{\mathrm{B}}$ \\
\hline 3 gün & $1111^{\mathrm{gh}}$ & $1125^{\mathrm{fgh}}$ & $1580^{\text {bcd }}$ & $1825^{\mathrm{a}}$ & $1410^{\mathrm{B}}$ \\
\hline 7 gün & $1035^{\mathrm{h}}$ & $1101^{\mathrm{gh}}$ & $1569^{\mathrm{bcd}}$ & $1803^{\mathrm{ab}}$ & $1377^{\mathrm{B}}$ \\
\hline 14 gün & $1154^{\mathrm{fgh}}$ & $1137^{\mathrm{fgh}}$ & $1623^{\mathrm{abc}}$ & $1704^{\mathrm{ab}}$ & $1405^{\mathrm{B}}$ \\
\hline 21 gün & $1286^{\mathrm{efg}}$ & $1426^{\text {cde }}$ & $1574^{\mathrm{bcd}}$ & $1599^{\mathrm{abc}}$ & $1471^{\mathrm{AB}}$ \\
\hline 28 gün & $1350^{\text {def }}$ & $1427^{\text {cde }}$ & $1592^{\mathrm{abc}}$ & $1734^{\mathrm{ab}}$ & $1526^{\mathrm{A}}$ \\
\hline Ortalama & $1205^{\mathrm{C}}$ & $1239^{\mathrm{C}}$ & $1544^{\mathrm{B}}$ & $1726^{\mathrm{A}}$ & - \\
\hline \multicolumn{6}{|c|}{ Ağırlık kaybı (\%) } \\
\hline Kontrol & $0,0^{\mathrm{k}}$ & $0,0^{\mathrm{k}}$ & $0,0^{\mathrm{k}}$ & $0,0^{\mathrm{k}}$ & $0,0^{\mathrm{F}}$ \\
\hline 3 gün & $7,1^{\mathrm{ij}}$ & $0,0^{\mathrm{k}}$ & $5,8 \mathrm{j}$ & $1,5^{\mathrm{k}}$ & $3,9^{\mathrm{E}}$ \\
\hline 7 gün & $21,9^{\text {cd }}$ & $6,1^{\mathrm{ij}}$ & $13,4^{\mathrm{f}}$ & $5,9^{\mathrm{ij}}$ & $11,8^{\mathrm{D}}$ \\
\hline 14 gün & $28,9^{\mathrm{b}}$ & $12,7^{\mathrm{f}}$ & $18,0^{\mathrm{e}}$ & $7,7^{\mathrm{hi}}$ & $16,8^{\mathrm{C}}$ \\
\hline 21 gün & $28,2^{\mathrm{b}}$ & $20,7^{\mathrm{d}}$ & $20,3^{\mathrm{d}}$ & $10,1^{\mathrm{g}}$ & $19,8^{\mathrm{B}}$ \\
\hline 28 gün & $35,1^{\mathrm{a}}$ & $21,4^{\mathrm{cd}}$ & $22,7^{\mathrm{c}}$ & $9,3^{\text {gh }}$ & $22,1^{\mathrm{A}}$ \\
\hline Ortalama & $20,2^{\mathrm{A}}$ & $10,4^{\mathrm{C}}$ & $13,3^{\mathrm{B}}$ & $5,7^{\mathrm{D}}$ & - \\
\hline \multicolumn{6}{|c|}{ Günlük ağırlık kaybı (\%) } \\
\hline Kontrol & $0,00^{j}$ & $0,00^{\mathrm{j}}$ & $0,00^{j}$ & $0,00^{j}$ & $0,00^{\mathrm{E}}$ \\
\hline 3 gün & $2,35^{\mathrm{b}}$ & $0,00^{\mathrm{j}}$ & $1,86^{\mathrm{c}}$ & $0,49^{\mathrm{hi}}$ & $1,17^{\mathrm{B}}$ \\
\hline 7 gün & $3,12^{\mathrm{a}}$ & $0,87^{\mathrm{fg}}$ & $1,91^{\mathrm{c}}$ & $0,84^{\mathrm{fg}}$ & $1,69^{\mathrm{A}}$ \\
\hline 14 gün & $2,06^{\mathrm{bc}}$ & $0,91^{\mathrm{f}}$ & $1,29^{\mathrm{de}}$ & $0,55^{\text {ghi }}$ & $1,20^{\mathrm{B}}$ \\
\hline 21 gün & $1,34^{\mathrm{d}}$ & $0,99^{\mathrm{ef}}$ & $0,96^{\mathrm{ef}}$ & $0,48^{\text {hi }}$ & $0,94^{\mathrm{C}}$ \\
\hline 28 gün & $1,26^{\mathrm{de}}$ & $0,76^{\mathrm{fgh}}$ & $0,81^{\text {fgh }}$ & $0,33^{\mathrm{i}}$ & $0,79^{\mathrm{D}}$ \\
\hline Ortalama & $1,69^{\mathrm{A}}$ & $0,69^{\mathrm{C}}$ & $1,13^{\mathrm{B}}$ & $0,45^{\mathrm{D}}$ & - \\
\hline
\end{tabular}

*: Aynı harfle gösterilen rakamlar arasında farklılık yoktur $(\mathrm{p}<0.05)$.

Şeker verimi hasat zamanı ve depolama sürelerinden önemli şekilde etkilenmiş ve en yüksek şeker verimi $1825 \mathrm{~kg} / \mathrm{da}$ ile 27 Ekim tarihinde hasat edilen ve 3 gün süreyle tarlada depolanan bitkilerden elde edilmiştir. 15 Eylül tarihinde hasat edilen bitkilerde en yüksek şeker verimi 1350 $\mathrm{kg} / \mathrm{da}$ ile 28 gün süreyle depolamada, 29 Eylül'de hasat edilen bitkilerde 21 ve 28 gün süreyle depolamada, 13 Ekim'de yapılan hasatta ise $1623 \mathrm{~kg} / \mathrm{da}$ ile 14 süreyle depolamada belirlenmiştir. Bulgularımızı destekler nitelikte olan Altunbay ve Kıllı'nın (2013) sonuçlarına göre, en yüksek şeker veriminin (957 kg/da) 20 Ekim ve 08 Kasım'da, Sefaoğlu ve ark. (2016) ise $1323 \mathrm{~kg} / \mathrm{da}$ olarak Kasım ayının ilk haftasında ve Ada ve Akınerdem (2011) ise $1401 \mathrm{~kg} / \mathrm{da}$ 'lık verim ile 15 Kasım'da hasat 
edilen şeker pancarından elde etmişlerdir. Abdollahian-Noghabi ve Zadeh (2005) en yüksek şeker verimini (10,54 ton/ha) 48 saat tarlada bekletildikten sonra depolanan pancarlarda belirlemiştir.

Hasat zamanı ve depolama sürelerine göre köklerdeki ağırlık kaybı önemli bulunmuş ve en yüksek ağırlık kaybı \%35,1 ile 15 Eylül tarihinde hasat edilen ve 28 gün süreyle tarlada depolanan pancarlarda gerçekleşmiştir. Tüm hasat zamanlarında tarlada depolama süresi uzadıkça ağırlık kaybı artmıştır. Erken hasat edilen bitkilerde uzun süre depolamada ağırlık kayıp oranı fazlayken, geç hasat edilen bitkilerde ağırlık kaybı erken hasada oranla daha az gerçekleşmiştir. Demirel ve Akınerdem (2016) tarla silolarında bekletilen pancarlarda çeşide göre \%29,9'a kadar ağırlık kaybının olabildiğini, Ada ve Akınerdem (2011) en fazla ağırlık kaybının 15 Eylülde hasat edilen pancarlarda, Ada ve Akınerdem (2006) farklı hasat tarihlerinin ortalamalarına göre ağırlık kaybının \%49,55 ile 60 gün süre ile yapılan silolamadan elde edildiğini ve en uygun silolamanın Ekim ayı içerisinde 30 gün süreyle yapılması gerektiği, Sarwar ve ark. (2008) depolama sırasında ağırlık kaybının çeşitlere göre değişebileceğini ve gölgede \%17,98, güneşte \%18,78 oranında ağırlık kaybı gerçekleştiğini bildirmişlerdir. Sonuçlarımız bu araştırıcıların bulgularını desteklemekte ve ağırlık kaybının depolama süresi uzadıkça arttı̆̆ını göstermektedir.

Günlük ağırlık kaybı hasat zamanı ve depolama sürelerinden önemli şekilde etkilenmiş ve en yüksek günlük ağırlık kaybı \%3,12 ile 15 Eylül tarihinde hasat edilen ve 7 gün süreyle tarlada depolanan pancarlarda gerçekleşmiştir. 13 Ekim ve 27 Ekim tarihlerinde de en yüksek günlük ağırlık kayıpları sırasıyla $\% 1,91$ ve $\% 0,84$ ile 7 gün süreyle depolanan pancarlardan elde edilmiştir. Yedi günden fazla sürede bekletilen pancarda günlük ağırlık kayıplarının azalmaya başladığı görülmektedir. $\mathrm{Bu}$ durum depolama süresi boyunca ilk 7 gün ağırlık kaybının çok hızlı olduğunu, daha sonra giderek azaldığını göstermektedir. 29 Eylül tarihinde hasat edilen pancarlarda günlük ağırlık kayıp oranının beklenenden düşük gerçekleşmesi mevsimsel yağış ve bulutluluktan kaynaklandığı düşünülmektedir. Çünkü, 29 Eylülde hasat edilen pancarlarda 3 gün depolama sonunda alınan 6,8 mm'lik yağış ağırlık kaybının azaltmıştır. Ayrıca, 30 Eylül-27 Ekim arasındaki dönemde de 35,3 mm'lik yağış gerçekleşmesi 29 Eylül hasadında ağırlık kaybının az olmasına neden olmuştur.

\section{Sonuc}

Şeker pancarında hasat zamanının tespiti, gerek verim gerekse şeker oranı bakımından büyük önem taşımaktadır. Genel olarak üreticiler, fabrikanın kampanya başlama zamanından birkaç gün önce şeker pancarı hasadına başlamaktadır. Bu ise çoğu zaman şeker pancarını hasadı için erken bir döneme rastlamaktadır. Üreticileri erken hasada yönelten en önemli faktör olarak pancar hasadından sonra yerine ekeceği buğday ve arpa bitkilerinin toprak hazırlığını ve ekim işlemlerini zamanında yapma kaygısı görülmektedir. Ayrıca, erken sonbahar yağışları nedeniyle de şeker pancarı hasadının istenildiği zamanda ve düzende yapılamaması, erken hasadın sebepleri arasında değerlendirilmektedir. Şeker pancarı birim alandan yüksek verim sağlayan bir ürün olduğu için hasat edilen ürünün tamamının fabrikaya aynı gün içinde taşınması ve fabrikada işlenmesi çoğunlukla mümkün olmamaktadır. Bazen fabrikada alım esnasında yaşanan aşırı yoğunluk nedeniyle de nakliyede problemler yaşanmakta ve hasat edilen pancarlar tarlada belirli sürelerde depolanmaktadır. Yürütülen bu çalışmada ise, Eskişehir Şeker Fabrikasının 2017 yılı kampanya döneminin başlangıcı olan 15 Eylül 2017 tarihinden başlamak üzere 15 gün aralıklarla düzenlenen dört hasat zamanında sökülen pancar köklerindeki yaklaşık bir ay tarlada depolanmış, ağırlık ve şeker oranındaki değişimler incelenmiştir.

Araştırma bulgularımız genel olarak değerlendirildiğinde, hasat zamanının geciktirilmesi şeker pancarında verimi $\% 8$ ve şeker oranını ise \%29,3 oranında arttırdığ edilen (15 Eylül) pancarlarda tarlada depolama süresinin uzaması kök-gövde ağırlığının \%35,1 oranında azaltırken, geç (27 Ekim) hasat edilen pancarlarda ağırlık sadece \%9,3 oranında azalmış, şeker oranı ise $\% 12,72$ 'den $\% 16,45^{\prime}$ 'e yükselmiştir. Geç hasat edilen pancarlarda depolama süresinin uzaması daha az ağırlık kaybına neden olmuştur. Bu durumun en önemli nedeni ise iklim koşulları olduğu düşünülmektedir. Çünkü Eylül ayında ortalama hava sıcaklığ $19,6^{\circ} \mathrm{C}$, Ekim ayında $10,7^{\circ} \mathrm{C}$ ve Kasım ayında ise $5,4^{\circ} \mathrm{C}$ olarak gerçekleşmiştir. Sıcak havalarda pancar köklerinden gerçekleşen su kaybının, verim azalmasına neden olduğu söylenebilir. Bununla birlikte, erken hasatta şeker oranı $\% 12,72$ olarak belirlenmiştir. $\mathrm{Bu}$ oran prime esas şeker oranı olan \%16'nın oldukça altında 
bulunmuştur. Erken hasat edilen bu pancarlarda asgari 14 gün süreyle tarla koşullarında depolama yapıldığında şeker oranının \%16'nın üzerine çıktığı belirlenmiştir.

Araştırma sonuçlarına göre, hasat zamanının özellikle şeker oranı üzerine önemli etkisinin olduğu söylenebilir. Hasattan sonra tarla koşullarında depolamanın ise kök ağırlığını azalttı̆̆ı, şeker oranını ise arttırdığı tespit edilmiştir. Erken hasatlarda tarlada depolamanın şeker pancarında daha fazla ağırlık kaybına neden olduğu, şeker oranını ise daha fazla arttırdığ 1 söylenebilir. Tarlada depolama esnasında iklim koşullarının özellikle yüksek sıcaklığın ağırlık kaybını hızlandırdığı, yağışın ve düşük sıcaklığın ise ağırlık kaybını azalttığı gözlenmiştir. Sonuç olarak, Eskişehir koşullarında şeker pancarında hasadın Ekim ayının ikinci yarısında yapılması ve bir haftadan daha uzun sürelerde tarlada depolanmamasının uygun olabileceği, ancak farklı çeşit kullanılarak birkaç yıl süreyle yapılacak araştırmalarla bu sonuçların desteklenmesi gerektiği söylenebilir.

\section{Teşekkür}

$\mathrm{Bu}$ çalışma, Eskişehir Osmangazi Üniversitesi Fen Bilimleri Enstitüsü tarafından kabul edilen Şerif Ferhat Koçak'ın yüksek lisans tezinden üretilmiştir. Araştırmada şeker analizlerinin yapımındaki katkılarından dolayı Kazım Taşkent Eskişehir Şeker Fabrikası kurumuna ve çalışanlarına teşekkür ederiz.

\section{Kaynaklar}

Abdel-Motagally, F.M.F., Attia, K.K., 2009. Response of sugar beet plants to nitrogen and potassium fertilization in sandy calcareous soil. International Journal of Agriculture and Biology, 11(6):695-700.

Abdollahian-Noghabi, M., Zadeh, R.O., 2005. Effect of harvesting operation procedure on the yield loss of sugar beet in Derzful. Iran. Int. Sugar J., 107: 354-356.

Ada, R., Akınerdem, F., 2006. Farklı zamanlarda hasat edilen ve silolanan şeker pancarında silolama süresinin verim ve kaliteye etkisi. Selçuk Üniversitesi Ziraat Fakültesi Dergisi, 20(39): 77-83.

Ada, R., Akınerdem, F., 2011. Farklı zamanlarda hasat edilen şeker pancarında (Beta vulgaris saccharifera L.) verim, kalite ve hasat kayıplarının belirlenmesi. Selçuk Üniversitesi Selçuk Tarım ve Gıda Bilimleri Dergisi, 25(1): 17-25.

Altunbay, S.G., Kıllı, F., 2013. Şekerpancarında (Beta vulgaris L.) çeşit-hasat zamanı interaksiyonu. Türkiye 10. Tarla Bitkileri Kongresi Bildiri Kitabı, Endüstri Bitkileri ve Biyoteknoloji, Cilt II, s. 203-207.

Anonim, 2017a. Pancar Ekicileri Kooperatifleri Birliği Dünya, AB ve Türkiye Şeker İstatistikleri, http://www.pankobirlik.com.tr/istatistikler.pdf, erişim tarihi 16.02.2018.

Anonim, 2017b. Türkiye şeker fabrikaları A.Ş. sektör raporu 2016 Mayıs 2017, s.31-34.

Anonim, 2018a. Şeker Pancarının Önemi, http://www.ereglipancar.com.tr/Kooperatif/Sayfa/ 2042, erişim tarihi 16.02 .2018

Anonim, 2018b. Türkiye İstatistik Kurumu, https://biruni.tuik.gov.tr/sanayidagitimapp/ sanayiuretim.zul, erişim tarihi 04.03.2018

Anonim, 2018c. Şeker Pancarı Tarımı, http://www.pankobirlik.com.tr/AnaSayfa/ Seker_Pancari_Tarimi, erişim tarihi 16.02 .2018

Anonim, 2019a. https://www.turkseker.gov.tr/SECTOR_REPORT.pdf, erişim tarihi 23.10.2019

Anonim, 2019b. http://www.endotar.com/urunler/bernache/, erişim tarihi 04.01.2019

Arıŏlu, H.H., 2000. Nişasta ve Şeker Bitkileri. Çukurova Üniversitesi Ziraat Fakültesi, Genel Yayın No:188, Ders Kitapları Yayin No:A-57, s. 234.

Barna, O., Baston, O., Daraba, A., 2011. Impact of temperature and storage time on sucrose content in sugar beet. Food Environ Saf - Journal of Faculty of Food Engineering, Ştefan cel Mare University, 10(2): 4447.

Can, R., 2016. Yozgat şartlarında farklı bölgelerde yetiştirilen şeker pancarının (Beta vulgaris L.) hasat zamanlarının verim ve kaliteye etkisi. Bozok Üniversitesi Fen Bilimleri Enstitüsü Tarla Bitkileri Anabilim Dalı, Yüksek Lisans Tezi, s. 64. (yayınlanmamış).

Demirel, D., Akınerdem, F., 2016. Farklı zamanlarda hasat edilen ve tarla silosunda bekletilen şeker pancarında silolama süresinin verim ve kaliteye etkisi. Selçuk Tarım Bilimleri Dergisi, 3(2): 143-156.

Er, C., Uranbey, S., 1998. Nişasta ve Şeker Bitkileri. Ankara Üniversitesi Ziraat Fakültesi Ders Kitabı, Yayın No 1504, s. 334.

Haagenson, D.M., Klotz, K.L., Campell, L.G., Khan, M.E.R., 2006. Relationship between root size and postharvest respiration rate. J. Sugar Beet Res., 43(4): 129-143.

Huijbregts, T., Legrand, G., Hoffmann, C., Olsson, R., Olsson, A., 2013. Long-term storage of sugar beet in North-West Europe. Coordination Beet Research International (COBRI), Report No:1, p.50. Goltze Druck GmbH\&Co. KG, Göttingen, Germany.

Kenter, C., Hoffmann, C.M., 2009. Changes in the processing quality of sugar beet (Beta vulgaris 1.) during long-term storage under controlled conditions. Int. J. Food Sci. Technol., 44: 910-917. 
ÇOMÜ Zir. Fak. Derg. (COMU J. Agric. Fac.)

2019: 7 (2): 313-321

ISSN: $2147-8384$ / e-ISSN: 2564-6826

doi: 10.33202/comuagri.565631

Kıllı, F., Altunbay, S.G., 2012. Kışlık şeker pancarı ekiminde çeşit ve hasat zamanlarının gövde verimi ve şeker oranına etkisi. 1. Uluslararası Anadolu Şeker Pancarı Sempozyumu, s. 143-146.

Kromer, K.H., Schmitz, S., 2004. Short time storage of sugar beets at the edge of field in heaps. Landtechnik, 59(2): 84-85.

Sarwar, M.A., Hussain, F., Ghaffar, A., Nadeem, M.A., Ahmad, M.M., 2008. Post-harvest studies in sugarbeet (Beta vulgaris). J. Agric. Soc. Sci., 4(2): 89-91.

Sefaoğlu, F., Kaya, C., Karakuş, A.. 2016. Farklı tarihlerde hasat edilen şeker pancarı genotiplerinin verim ve verim unsurlarının belirlenmesi. Tarla Bitkileri Merkez Araştırma Enstitüsü Dergisi, 25(Özel Sayı 2): 61-66.

Tok, S., Erkan, S., 2006. Bursa ve Çanakkale illerinde bazı yörelerde yetiştirilen şeker pancarı bitkilerindeki virüs hastalıklarının saptanması. Ege Üniversitesi Ziraat Fakültesi Dergisi, 43(1): 45-53. 